\title{
The Pattern of Maxillofacial Trauma \& its Management
}

Syed Amjad Shah ${ }^{1 *}$, Zahid Qayyum Bangash², Tahir Ullah Khan ${ }^{3}$, Muhammad Yunas ${ }^{4}$,

\section{Muhammad Raza ${ }^{5}$, Syed Fahim Shah ${ }^{6}$}

${ }^{1}$ Vice Principal, Professor \& Head Department of Oral and Maxillofacial Surgery, Ripha International University, Pakistan. ${ }^{2}$ Assistant Professor Oral and Maxillofacial Surgery Margalla College of Dentistry Rawalpindi, University of Health Sciences, Pakistan. ${ }^{3}$ Assistant Professor Oral and Maxillofacial Surgery Peshawar Dental College, Ripha International University, Pakistan.

${ }^{4}$ Assistant Professor Oral Medicine Peshawar Dental College, Ripha International University, Pakistan.

${ }^{5}$ Assistant Professor Prosthodontics, Peshawar Dental College, Ripha International University, Pakistan.

${ }^{6}$ Associate Professor Medicine Institute of Medical Sciences Kohat, Khyber Medical University Pakistan.

Received: September 09, 2016; Accepted: October 05, 2016; Published: November 22, 2016

*Corresponding author: Amjad Shah Syed, Vice Principal, Head Department Of Oral And Maxillofacial Surgery, Peshawar Dental College Warsak Road Peshawar, Ripha International University, Pakistan.Tel: +923339107122; E-Mail: Amjadshahsyed@Gmail.Com

\begin{abstract}
Purpose: The descriptive study was undertaken to determine the pattern and different methods of treatment of maxillofacial fractures.

Materials and Methods: Three hundred and twenty consecutive patients with maxillofacial trauma were treated in a tertiary care hospital in last three years. A review of patients' records and radiographs was conducted. Data regarding age, gender, cause of fracture, anatomic site and treatment modalities were reviewed.
\end{abstract}

Results: The age range was 2-76years (25 \pm 8 ) with peak frequency occurring in age group 21-30 years. The male to female ratio was 5.4: 1. The study indicated that $(\mathrm{n}=206 ; 64.7 \%)$ resulted from road traffic accidents (rtas) followed by fall ( $\mathrm{n}=60 ; 18.8 \%)$, assault $(\mathrm{n}=26 ; 8.1 \%)$, sports $(n=17 ; 5.3 \%)$, firearm injury [FAI $(n=3 ; 0.9 \%)]$, industrial trauma $(n=2 ; 0.6 \%)$ while 5 cases $(1.65 \%)$ were associated with other causes such as bomb blast, animal injury etc.

The mandible was the most commonly involved (69.7\%) followed by zygomatic complex [ZC $(8.4 \%)]$, maxilla $(5.3 \%)$, nasal bone $(1.3 \%)$ and nasoethmoidal fractures $(0.9 \%)$; in $14.4 \%$ of cases, more than one facial bone fracture occurred. Of mandibular fractures, body (30.3\%) was the most common site followed by condylar region $(24.2 \%)$. In midface fractures the $\mathrm{ZC}$ was the most susceptible area $(48.2 \%$ of midface); of maxillary fractures, Le Fort I was the most common fracture $(34.5 \%)$; the frequency of nasal $(7.1 \%)$ \& nasoethmoidal $(5.4 \%)$ remained low. Most patients with mandibular fractures were treated by closed reduction surgery [eyelet wiring, arch bars with inter maxillary fixation (IMF) \&splint fixation], only $18.9 \%$ of patients were treated with open reduction surgery (Interosseous \&miniplates fixation). The maxillary fractures were mostly treated with suspension wiring while in ZC fractures Gillies' approach (37.9\%) was the common method of management.

Conclusion: This study reflects trauma patterns within the community and, as such, can provide a guide to the design of programs geared toward prevention and treatment.

Keywords Trauma; Facial Fractures;

\section{Introduction}

The face, as most exposed part of the body, is particularly vulnerable to trauma. [1] The main causes worldwide are road traffic accidents, falls, assaults, sports, firearm injuries and industrial trauma. [3, 14, 25]Clearly, the etiology would be expected to influence the degree and type of injury sustained. [4] Data collected from the 1960s and early 1970s have indicated that $20 \%-60 \%$ of all people injured in R.T. As has some degree of maxillofacial injury. [5] A high incidence of maxillofacial injuries due to R.T.As is reported in developing nations, while incidence due to personal violence is more in developed countries. [6] Introduction of compulsory seat belts and drinkdrive legislation[7] have significantly reduced both the number and severity of injuries sustained following road traffic accidents by $25 \%$,and the more serious facial injuries reduced in severity by two-third. [8] it is found that falls were the $2^{\text {nd }}$ most common cause after assault though it is recognized that many patients who have assaulted reported that their injuries were due to falls. $[3,9]$ The constant improvement in the quality of individual life and growing interest in sporting activities have resulted in an increased use of sport in free time at the amateur level. As a result, sports injuries have steadily increased. [10,11] Maxillofacial trauma due to firearm injuries has been increasing during the past decades, being one of the greatest challenges for oral maxillofacial surgeons. ${ }^{12}$ Greater industrial trauma is reported in industrialized cities.

When the maxillofacial region is injured the most common facial fractures involve the mandible followed by the ZC, maxilla, and alveolar process [14]. Some authors have reported zygoma as a more susceptible bone than the maxilla. [13] The fracture may involve a combination of two or more facial bones. The most favorable sites of fractures (in descending order) in the mandible are the parasymphysis, body, angle, condoler region, symphysis, and coronoid process [15]. 
Age and sex have been cited as important factors that influence the occurrence of maxillofacial injuries. The highest incidence is seen in the age group 20-40 years. The lowest incidence is observed in the age group above 60 years and below 5 years. Most of the patients are male with a male: female ratio of approximately 3:1. [16]

Over the past 100 years, Major developments have been made in the care of victims of maxillofacial trauma such as external skeletal fixation, open reduction, craniofacial exposure, internal wire fixation, primary bone grafting, miniplates and orbital reconstruction. Therefore, such injuries adversely affect the quality of life less frequently today than once did, due to the advances that have been made by countless individuals from diverse disciplinary backgrounds. Collectively, these advances have provided great improvement in the primary and secondary correction of traumatic maxillofacial deformities.

The study was carried out to determine the pattern of oral and maxillofacial trauma and to describe different trends in the management of maxillofacial fractures. This study may provide circumstantial evidence for the recommendation of possible preventive measures. For example, the introduction of seat belt legislation in developed countries, as expected led to a drop in the incidence of maxillofacial injuries resulting from road traffic accidents.

\section{Material and Methods}

The information obtained was based upon analysis of maxillofacial injuries recorded from the department of Oral \& maxillofacial Surgery, de' Montmorency college of Dentistry, Lahore during last three years. The descriptive randomized study was conducted on three hundred and twenty consecutive patients as having received maxillofacial injuries. The Sampling technique was non-probability.

\section{Inclusion criteria}

All patients of any age and either sex presenting with maxillofacial trauma to the department were included in the study.

\section{Exclusion criteria}

1. The fractures, which did not need surgical intervention for cosmetic restoration or function improvement

2. Previously maltreated cases.

3. Too old fractures with malunion.

4. Patients having contra-indications for local \& general anesthesia.

\section{Data Collection Procedure}

A detailed history of the patient was taken and thorough clinical examination was carried out. Then a specially designed detailed perform (annexure 'a') was filled up. Basic investigations and specific investigations like radiograph such as intra-oral; 0 . P.g (ortho pantomogram); p.a (postero anterior) mandible; p.n.s (paranasal sinuses), $\left(10^{\circ}\right.$ and $\left.30^{\circ}\right)$ and submentovertical were carried out to confirm the bony trauma. The fractures were classified according to standard nomenclature. An appropriate management plan was devised and followed up for 6 weeks. The pattern and management of maxillofacial trauma were compiled according to the age, sex, etiology, site, relative frequency and methods of fixation.

On an outpatient basis, simple methods of closed reduction and immobilization were used for mandibular fractures, with patients under local anesthesia. Imf (erich arch bar with elastics) was used for condylar fractures and imf (eyelet wiring) was performed for favorable mandibular fractures.

The patients below 15 years were treated under ga (general anesthesia) because of their uncooperative behavior. The splint fixation was preferred for edentulous patients and for children.

The elevations of $\mathrm{zc}$ fractures and circum-zygomatic suspensions for maxillary fractures were performed, with patients under ga.

Open reduction was used in cases of unfavorable fractures atan angle of the mandible and multiple fractures that were difficult to maintain with an arch bar or imf (eyelet wiring), and whenever closed reduction would not maintain the fractured fragments as for example, in severe injuries with significant displacement.

Data Analysis: the data so collected were evaluated with chi square $\left(x^{2}\right)$ test of significance and the results analyzed statistically by applying spss v16 and findings were presented as such.

\section{Results}

\section{Etiology}

During the three years period; 320 patients with different types of maxillofacial fractures were treated. The most common cause of maxillofacial trauma was rtas ( $n=207 ; 64.7 \%)$, followed by accidental fall $(n=60 ; 18.8)$ and injuries associated with the fight $(n=26 ; 8.1 \%)$; the remaining fractures were due to a variety of causes, including sports-related injuries in 17 cases (5.3\%). The causes of injuries are shown in figure 1. There was no significant difference between the genders regarding etiology $(p=0.110)$

\section{Age and Gender Distribution}

The age of the patient at the time of injury ranged from 2-76 years, with a mean age of 25 years \pm 13 years. In most cases, the patient was between the age of 21-30 years ( $\mathrm{n}=105 ; 32.8 \%)$. Only $12.8 \%$ of patients were less than 11years of age, and $1.3 \%$ was more than 60 years of age (figure 3 ). In virtually all age groups, more men than women were affected, the overall ratio being 5.4:1(figure 2). P value (0.240) shows no difference between the different age groups regarding causes of injury.

\section{Sites of Fractures}

The most frequent bone fractured was the mandible, which accounted for 223 cases (69.7\%), the ZC in 27 cases (8.4\%), the 
maxilla in 17 cases (5.3\%), followed by nasal and nasoethmoidal fractures as shown in figure 4.

$14.4 \%$ of cases involved combination fractures; of these thirty-four patients $(10.6 \%)$ sustained fractures of mandible and ZC; 7 patients $(2.2 \%)$, of the mandible and maxilla; 5 patients (1.6\%), of maxilla \& ZC (figure 4).

The distribution of the mandibular fractures is detailed in tables 1,2 . The most common site was body of the mandible (30.3\%), followed by condylar process $(24.2 \%)$, angle $(21.6 \%)$, parasymphysis (10.6\%), dent alveolar, (5.7\%) symphysis (4.9\%), ramus $(1.9 \%)$ and the coronoid process $(8 \%)$.

The distribution of maxillary fractures (table $1 \& 4$ ) was Le Fort in 10 cases (34.5\%), Le Fort II in 8 (27.6\%), the alveolar process in 7 (24.1\%), and Le Fort III in 4 (13.8\%) patients. Of zygomatic fractures (tables $1 \& 6$ ), the zygomatic bone was involved in 57 cases (86.4\%) and the arch was fractured in only 9 cases $(13.6 \%)$. Nasal \&nasoethmoidal fractures were found in five and 3 cases respectively as shown in table 1.There were no significant difference between etiology and fracture site $(\mathrm{p}=$ 0.502).

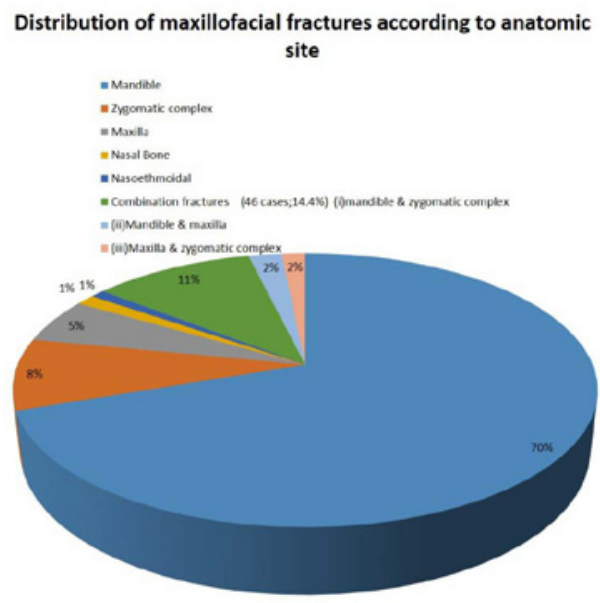

Figure 1

\section{Distribution of maxillofacial fractures according to age}

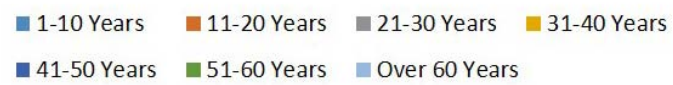

- $51-60$ Years 60 Years

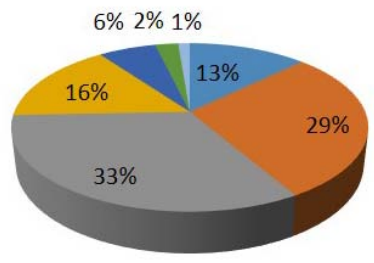

Figure 2

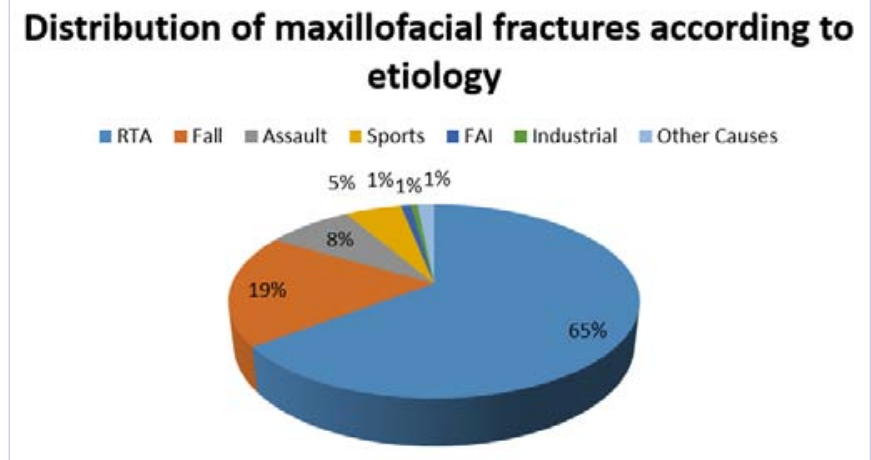

Figure 3

\section{Distribution of maxillofacial fractures according to sex}

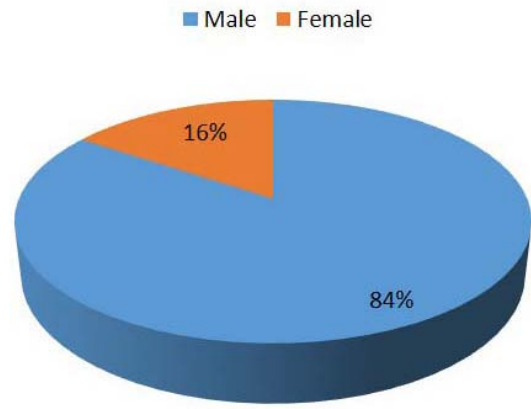

Figure 4

\begin{tabular}{|c|c|c|}
\hline & $\begin{array}{l}\text { number of } \\
\text { cases }\end{array}$ & percent \\
\hline Mandibular fracture & 223 & 62.6 \\
\hline Maxillary fracture & 17 & 4.7 \\
\hline zygomatic complex fracture & 7 & 1.9 \\
\hline Midface fracture & 56 & 15.7 \\
\hline Mandibular \& Maxillary fracture & 7 & 1.9 \\
\hline Mandibular \& Zygomatic fracture & 34 & 9.5 \\
\hline Mandibular+ Maxillary+ Zygomatic fracture & 5 & 1.4 \\
\hline Nasal fracture & 4 & 1.2 \\
\hline Nasoethmoidal & 3 & 0.8 \\
\hline Total & 356 & 100 \\
\hline
\end{tabular}

\section{Treatment}

Several methods of reduction and fixation were used in the treatment of mandibular fractures as shown in table 3. Of the 264 mandibular fractures, 214 cases $(81 \%)$ were treated by closed reduction; 106(40.2\%) of these with IMF (eyelet wiring), $65(24.6 \%)$ with arch bars and IMF used to treat condylar fractures, $28(10.6 \%)$ with splint fixation mostly used for children 
and edentulous patients. Only $50(19 \%)$ patients were treated by open reduction and fixation with interosseous wiring and main plates.

Le Fort fractures were treated with circum-zygomatic suspension wiring, interosseousand manipulate fixation (table 5). The most of Le Fort I fractures were managed with wire suspension (31\%) whereas in Le Fort II and Le Fort III open reduction with interosseous $(24.1 \%)$ and miniplate fixation (20.7\%) was performed. All such cases were supported by IMF. However, in internal rigid fixation, early removal of IMF was advised. The plain arch bar (half round wire) was used to treat maxillary dent alveolar fractures

Of ZC fractures, 25 cases (37.9\%) were reduced through the use of the Gillies' temporal approach whereas $14(21.2 \%)$ patients were treated with the transoral approach. The open reduction was performed in 21 cases (31.8\%); 18.2\% \& 13.6\% of these were treated with interosseous wiring and miniplate fixation respectively. Only 6 cases $(9.1 \%)$ were managed conservatively with observation alone as shown in table 7. In Nasal bone fracture, 2 cases were treated with close reduction whereas one fracture with open reduction (table 8). Open reduction was used to treat all the three nasoethmoidal fractures.

\section{Discussion}

The result of epidemiological surveys on the causes and incidence of maxillofacial fractures tend to vary with geographic region, socioeconomic status, culture, religion and era. [14] The predominance of maxillofacial trauma in the age group 21-30 years is consistent with the findings of previously published work. But contrasts with the report of Karyouti, [17] who gave the age group of 0-5 years as having the highest incidence. The possible explanation for the high frequency of the 21-30 year age group is that people in this age group take part in dangerous exercises and sports, drive motor vehicles carelessly, and are most likely to be involved in violence. The lowest frequency was observed in the age group above 60 years $(1.3 \%)$ contrary to the study of Kapoor and Srivastava [18] in which it was 0-5 years. The limited outdoor activities in old age would be the possible reason.

Most of the studies ${ }^{3}$ have shown a higher incidence of maxillofacial fractures in males than females. In this study, it remained 5.4:1 that is higher than reported by Boffano $\mathrm{P}$ et al (2.2:1).[14] The higher age of man could be because men are mostly involved in outdoor activities and are also exposed to violent interaction. Male drivers are more as compared to female.

In most previous epidemiological studies traffic accidents were the most common cause of maxillofacial fractures, [3,14,24] and the present study supports these findings. In England, it has been reported that the introduction of the compulsory use of seat belts is having a significant effect with respect to reducing the number of facial injuries.[7] In Pakistan, a law making the use of seat belts compulsory has not been implemented properly. While interviewing the victims of facial trauma due to rtas, it was
Table 2. Distribution of mandibular fractures according to anatomic site.

\begin{tabular}{|l|c|c|}
\hline & number of cases & percent \\
\hline Body & 80 & 30.3 \\
\hline Condyler & 64 & 24.2 \\
\hline Angle & 57 & 21.6 \\
\hline Parasymphysis & 28 & 10.6 \\
\hline Dentoalveolar & 15 & 5.7 \\
\hline Symphysis & 13 & 4.9 \\
\hline Ramus & 5 & 1.9 \\
\hline Coronoid & 2 & 0.8 \\
\hline Total & 264 & 100 \\
\hline
\end{tabular}

Table 3. Methods of fixation for mandibular fractures.

\begin{tabular}{|l|c|c|}
\hline & $\begin{array}{c}\text { number of } \\
\text { cases }\end{array}$ & percent \\
\hline IMF(eyelet wiring) & 106 & 40.2 \\
\hline IMF(arch bar+elastics) & 65 & 24.6 \\
\hline Splint fixation & 28 & 10.6 \\
\hline Interosseous wiring with IMF & 28 & 10.6 \\
\hline Miniplates fixation with IMF & 22 & 8.3 \\
\hline Plain arch bar & 15 & 5.7 \\
\hline Total & 264 & 100 \\
\hline
\end{tabular}

Table 4. Distribution of maxillary fractures.

\begin{tabular}{|l|c|c|}
\hline & $\begin{array}{c}\text { number of } \\
\text { cases }\end{array}$ & percent \\
\hline Le Fort I & 10 & 34.5 \\
\hline Le Fort II & 8 & 27.6 \\
\hline Maxillary dentoalveolar & 7 & 24.1 \\
\hline Le Fort III & 4 & 13.8 \\
\hline Total & 29 & 100 \\
\hline
\end{tabular}

Table 5. Methods of fixation for maxillary factures

\begin{tabular}{|l|c|c|}
\hline & $\begin{array}{c}\text { number of } \\
\text { cases }\end{array}$ & percent \\
\hline Suspenion wiring with IMF & 9 & 31 \\
\hline Interosseous wiring with IMF & 7 & 24.1 \\
\hline Plane arch bar & 7 & 24.1 \\
\hline Miniplate fixation with IMF & 6 & 20.7 \\
\hline Total & 29 & 100 \\
\hline
\end{tabular}

Table 6. Zygomatic complex fractures(anatomic site).

\begin{tabular}{|l|c|c|}
\hline & number of cases & percent \\
\hline Zygomatic bone & 57 & 86.4 \\
\hline Zygomatic arch & 9 & 13.6 \\
\hline Total & 66 & 100 \\
\hline
\end{tabular}


observed that the carelessness of many drivers, failure to give the right of way, excessive speed on highways for competition among addict drivers, were responsible for the increase in a number of maxillofacial fractures due to R.T.As.

Islam S et al [9] and Mijiti A [18] reported the assault as the predominant cause of maxillofacial fractures in England and China, respectively. The frequency of $8.1 \%$ in this study caused by fighting contrast vividly with their studies, a finding that may be related to differences in social customs alcohol intake. Because of religious background, Pakistanis do not drink alcohol.

When the maxillofacial region is injured, the mandible is more vulnerable than the mid face fractures [14]. This could be because the mandible is mobile and has less bony support than mid facial bones. These fractures are, however, more common in certain sites of the mandible than others. Almost all studies showed that the body of the mandible was the most frequently affected area. The least affected site is the coronoid process [25].

In this study condylar region of the mandible is the $2^{\text {nd }}$ most commonly involved site, which is in contrast with figures obtained from studies in Nigeria [1] and Jordan. [3] It is difficult to cite a reason for this difference; perhaps a further study on the causes of the regional mandibular fractures would be useful. One can speculate that inter-population difference in the sites of maxillofacial fractures partly related to the diverse etiologic factors involved. Zhou HH et al [26] observed similar results

Several studies have suggested that mandibular fractures can be treated by closed reduction and I.M.F $[19,20]$. Olson et al [21] and Hill et al [22] concluded that most mandibular fractures were amenable to management by Closed Reduction. Of the 264 patients in our series, only 50 of mandibular fractures had required open reduction. All methods were used for fixation without the use of any devices for external fixation. Furthermore,

Table 7. Treatment of zygomatic complex fractures.

\begin{tabular}{|l|c|c|}
\hline & $\begin{array}{c}\text { number of } \\
\text { cases }\end{array}$ & percent \\
\hline Temporal fossa approach & 25 & 37.9 \\
\hline Transoral approach & 14 & 21.2 \\
\hline Open reduction with interosseous wiring & 12 & 18.2 \\
\hline Open reduction with miniplates fixation & 9 & 13.6 \\
\hline Conservative treatment & 6 & 9.1 \\
\hline Total & 66 & 100 \\
\hline
\end{tabular}

Table 8. Treatment of nasal fractures.

\begin{tabular}{|l|c|c|}
\hline & $\begin{array}{c}\text { number of } \\
\text { cases }\end{array}$ & percent \\
\hline Closed reduction with tape \& plaster & 2 & 50 \\
\hline Closed reduction with manipulation & 1 & 25 \\
\hline Open reduction & 1 & 25 \\
\hline Total & 4 & 100 \\
\hline
\end{tabular}

simple methods of Reduction and Immobilization were used on an outpatient basis under local anesthesia. And the results were satisfactory.

In mid face region, the $\mathrm{ZC}$ was the most susceptible area. This coincides with the views of Baylan JM et al, [23] who reported that zygoma was the most common site of fractures in the middle $3^{\text {rd }}$ of the face. The low frequency of fractures of mid face in our session may be because we lack modern radiological techniques such as C.T scan and loss of patients to other specialties especially nasal fractures are routinely treated by E.N.T surgeons. The simple methods of reduction and fixation were used for mid face and results were satisfactory.

The use of mini plate has become increasingly popular for the management of maxillofacial fractures in recent years $[27,28,29]$. In this study, 33 cases of mid face were treated with miniplate fixation. The reason for the low frequency of rigid internal fixation is the poor economic conditions of patients [30] and simple methods of the fixation give satisfactory results. However, advantages and effectiveness versus the cost of miniplates fixation need further study in our region.

\section{Conclusion}

The present study revealed that the peak frequency of maxillofacial fractures occurred in the age group consisting of 2130 years old and most frequent cause was R.T.As (64.7\%). The male to female ratio was 5.4:1. The predominant fractured bone was the mandible $(69.7 \%)$ and the body $(30.3 \%$ of mandibular fractures) was the most frequent site followed by condylar region $(24.2 \%)$. In mid face, the zygomatic complex was the most susceptible area (48.2\% of mid face). Most fractures were neither severe not complicated and were successively treated by the conventional mean. The most commonly used technique was a closed reduction.

There are obvious limitations to our data, such as the exclusion of cases from related specialties, lack of modern diagnostic methods and poor economic condition of the patients. Despite these limitations, the findings show that there are causes of concern about the high rate of maxillofacial injuries caused by R.T.As, as few people use safety belts, an awareness campaign to educate the public especially drivers about the importance of restraints and protective measures in motor vehicles, should be implemented. These finding should alert the authorities to the need for the enforcement of existing traffic laws to control excessive speed on highways and careless driving; provision of better roads; and the use of safety belts is to be made compulsory.

\section{References}

1. Olusanya AA, Adeleye AO, Aladelusi TO, Fasola AO. Updates on the epidemiology and pattern of traumatic maxillofacial injuries in a nigerian university teaching hospital: a 12-month prospective cohort in-hospital outcome study.Craniomaxillofac Trauma Reconstr.2015;8(1):50-58. doi: 10.1055/s-0034-1384740.

2. Bart van den Bergha, K. HakkiKaragozoglua, Martijn W. Heymansb, Tymour Forouzanfara. Aetiology and incidence of maxillo facial trauma in Amsterdam: A retrospectiveanalysis of 579 patients. 
JCraniomaxillofacSurg. 2012;40(6): 165-169. doi: 10.1016/j. jcms.2011.08.006.

3. Tugaineyo EI, Odhiambo WA, Akama MK, Guthua SW, Dimba EA Aetiology, pattern and management of oral and maxillofacial injuries at mulago national referral hospital. East Afr Med J.2012;89(11):351358.

4. Adi M, Ogden G R, Chisholm D M. An analysis of mandibular fractures in Dundee, Scottland (1977 to 1985). Br J Oral MaxillofacSurg.1990;28(3):194-99.

5. Nahum AM, Siegel AW, Brooks S. The reduction of collision injuries, past, present, and future. In: proc 14th STAPP Car Conference, New York: Society of Automobile Engineers, 1970:1-43.

6. Kyrgidis A, Koloutsos G, Kommata A, Lazarides N, Antoniades K. Incidence, aetiology, treatment outcome and complications of maxillofacial fractures. A retrospective study from Northern Greece. CraniomaxillofacSurg. 2013; 41(7):637-643. doi: 10.1016/j. jcms.2012.11.046.

7. Ion Holland. Trauma. In: Newlands N, Kerawala C. Oral and Maxillofacial Surgery Oxford Specialist Handbooks in Surgery. $2^{\text {nd }}$ Ed. UK: Oxford University Press; 2014. 1-62.

8. Nakamura T, Gross CW. Facial fractures: analysis of five years of experience. Arch Otolaryngol .1973;97(3):288-90.

9. Islam S, Uwadiae N, Hayter JP. Assault-related facial injuries during the season of goodwill.Oral Surg Oral Med Oral Pathol Oral Radiol. 2016;121(6):139-142. doi: 10.1016/j.oooo.2016.01.012.

10. Murphy C, O'Connell JE, Kearns G, Stassen L. Sports-Related Maxillofacial Injuries.J CraniofacSurg. 2015;26(7):2120-2123. doi: 10.1097/SCS.0000000000002109.

11. Ruslin M, Boffano P, ten Brincke YJ, Forouzanfar T, Brand HS. SportRelated Maxillo-Facial Fractures.J CraniofacSurg. 2016;27(1):91-94. doi: 10.1097/SCS.0000000000002242.

12. Motamedi MH. Management of firearm injuries to the facial skeleton Outcomes from early primary intervention. J Emerg Trauma Shock. 2011;4(2):212-216. doi: 10.4103/0974-2700.82208.

13. De Gioanni PP, Mazzeo R, Servadio F. Sport's activities and maxillofacial injuries. Current epidemiologic and clinical aspects relating to a series of 379 cases (1982-1998). Minerva Stomatol. 2000;49(1-2):21-26.

14. Boffano P, Roccia F, Zavattero E, Dediol E, Uglešić V, Kovačič Ž, et al. European Maxillofacial Trauma (EURMAT) project: a multicentre and prospective study. Jcraniomaxillofacsurg .2015;43(1):62-70. Doi: 10.1016/j.jcms.2014.10.011

15. Oruç M, Ișik VM, Kankaya Y, Gürsoy K, Sungur N, Aslan G,et all. Analysis of Fractured Mandible Over Two Decades. J CraniofacSurg. 2016;27(6):1457-1461. doi: 10.1097/SCS.0000000000002737.

16. Singaram M, G SV, UdhayakumarRK. Prevalence, pattern, etiology, and management of maxillofacial trauma in a developing country: a retrospective study. J Korean Assoc Oral MaxillofacSurg. 2016;42(4):174-181. doi: 10.5125/jkaoms.2016.42.4.174.
17. Iida S, Kogo M, Sugiura T, Mima T, Matsuya T. Retrospective analysis of 1502 patients with facial fractures. Int J Oral MaxillofacSurg. 2001;30(4):286-290. DOI: 10.1054/ijom.2001.0056.

18. Mijiti A, Ling W, Tuerdi M, Maimaiti A, Tuerxun J, Tao YZ, et all. Epidemiological analysis of maxillofacial fractures treated at a university hospital, Xinjiang, China: A 5-year retrospective study.J CraniomaxillofacSurg.2014;42(3):227-233. doi: 10.1016/j. jcms.2013.05.005.

19. Theologie-Lygidakis N, Chatzidimitriou K, Tzerbos F, Gouzioti A, Iatrou I.Nonsurgical management of condylar fractures in children: A 15-year clinical retrospective study.JCraniomaxillofacSurg.2016;44(2):85-93. doi: 10.1016/j.jcms.2015.11.011.

20. Muñante-Cárdenas JL, Olate S, Asprino L, de Albergaria Barbosa JR, de MoraesM,MoreiraRW.Patternand treatmentoffacialtraumain pediatric and adolescent patients.J CraniofacSurg.2011;22(4):1251-1255. doi: 10.1097/SCS.0b013e31821c696c.

21. Gilmer TL. A case of fracture of the lower jaw with remarks on the treatment. Arch Dent.1969;43(3):304-305.

22. Gilmer TL. Fractures of inferior maxilla. Ill St Dent Soc Trans 1881; 67:67.

23. BaylanJM,JupiterD,ParkerWL,CzerwinskiM.ManagementofZygomatic Fractures: A National Survey. J CraniofacSurg.2016;27(6):1571-1575. doi: $10.1097 /$ SCS.0000000000002880.

24. Moore BK, Smit R, Colquhoun A, Thompson WM. Maxillofacial fractures at Waikato Hospital, New Zealand: 2004 to 2013.N Z Med J. 2015;128(1426):96-102.

25. Arangio P, Vellone V, Torre U, Calafati V, Capriotti M, Cascone P.Maxillofacial fractures in the province of Latina, Lazio, Italy: review of 400 injuries and 83 cases.J CraniomaxillofacSurg. 2014;42(5):583587.DOI: dx.doi.org/10.1016/j.jcms.2013.07.030.

26.Zhou HH, Liu Q, Cheng G, Li ZB. Aetiology, pattern and treatment of mandibular condylar fractures in 549 patients: a 22-year retrospective study.JCraniomaxillofacSurg. 2013;41(1):34-41. doi: 10.1016/j. jcms.2012.05.007.

27. Ellis E 3rd. Open reduction and internal fixation of combined angle and body/symphysis fractures of themandible: how much fixation is enough? J Oral Maxillofac Surg. 2013;71(4):726733. doi: 10.1016/j. joms.2012.09.017.

28. AlMoraissi EA, Ellis E. Surgical management of anterior mandibular fractures: a systematic review andmetaanalysis. J Oral Maxillofac Surg. 2014;72(12):2507.e1 11. doi: 10.1016/j.joms.2014.07.042.

29. Curtis W, Horswell BB. Panfacial fractures: an approach to management. Oral MaxillofacSurgClin North Am. 2013; 25(4):649660. doi: 10.1016/j.coms.2013.07.010.

30. Nalliah RP, Allareddy V, Kim MK, Venugopalan SR, Gajendrareddy $\mathrm{P}$, Allareddy V. Economics of facialfracture reductions in the United States over 12 months. Dent Traumatol. 2013;29(2):115120. DOI: 10.1111/j.1600-9657.2012.01137.x. 